\title{
Políticas públicas LGBT: uma análise do programa Transcidadania da prefeitura de São Paulo
}

\author{
Émerson Silva Santos ${ }^{I}$ \\ Cleyton Feitosa Pereira ${ }^{I I}$
}

Resumo: Este trabalho tem por objetivo analisar o Programa TransCidadania da Prefeitura de São Paulo, descrevendo suas ações e formas de atuação para o enfrentamento da transfobia e promoção da cidadania de travestis e transexuais naquele município. Desta forma, analisamos esta política pública através do seu decreto de criação, o Decreto 55874/2015, que demonstra detalhes, seja da concepção adotada pelo atual governo do município de São Paulo, seja do desenvolvimento e execução desta política junto à população trans paulistana. Os resultados apontam que 0 TransCidadania é um programa em fase inicial, de experimentação que prevê um conjunto de medidas que garantam o acesso a direitos básicos do público-alvo como a Educação, Saúde, Assistência Social, entre outros e prevê o empoderamento identitário como elemento fortalecedor da cidadania.

Palavras-Chave: Direitos Humanos, Políticas Públicas LGBT, Gênero, Transexualidade.

\section{LGBT public policies: an analysis of the Transcitizenship program of the São Paulo city hall}

Abstract: The purpose of this study is to analyze the TransCitizenship Program of the City of São Paulo, describing its actions and ways of acting to confront transphobia and promote the citizenship of transvestites and transsexuals in that city. In this way, we analyze this public policy through its decree of creation, Decree 55874/2015, which demonstrates details, either of the conception adopted by the current government of the city of São Paulo, or of the development and execution of this policy with the Trans-São Paulo population. The results indicate that the TransCitizenship is an initial program of experimentation that provides a set of measures that guarantee access to basic rights of the target public such as Education, Health, Social Assistance, among others and provides for the empowerment of identity as an element strengthening of citizenship.

Keywords: Human Rights, LGBT Public Policy, Gender, Transsexuality.

Artigo recebido em 04/01/2017 e aprovado em 12/03/2017. 


\title{
POLÍTICAS PÚBLICAS LGBT: UMA ANÁLISE DO PROGRAMA TRANSCIDADANIA DA PREFEITURA DE SÃO PAULO
}

\author{
ÉMERSON SILVA SANTOS E CLEYTON FEITOSA PEREIRA
}

\section{Introdução}

A situação social das pessoas travestis e transexuais no Brasil é, no mínimo, preocupante. Temos assistido a uma série de negação e violações de direitos humanos como o acesso à educação, saúde, moradia, emprego e renda, entre outros. Soma-se a isso, uma elevada taxa de assassinatos contra essa população. Essa realidade nos motivou a analisar uma política pública voltada especificamente para o segmento trans.

Compreendendo que há uma polissemia de compreensões acerca da transexualidade, inclusive patológica partindo dos setores científicos conservadores da Medicina, utilizaremos a compreensão de Carvalho, Andrade e Junqueira que, baseados em Berenice Bento, ilustram:

\begin{abstract}
Segundo Berenice Bento, a transexualidade é uma experiência identitária caracterizada pelo conflito com as normas de gênero e pela reivindicação e reconhecimento de uma nova identidade de sexo e de gênero, segundo as subjetividades e narrativas dos próprios sujeitos. Contrariando o discurso médico tradicional, a transexualidade não é uma "doença mental" (denominada "disforia de gênero") e nem se define necessariamente pela expressão do desejo de alterar cirurgicamente a anatomia sexual da pessoa. Transexual é toda pessoa que reivindica o reconhecimento social e jurídico de uma identidade de sexo/gênero diferente daquela que lhe foi atribuída/imposta no momento de seu nascimento ou após ele. Para que as pessoas transexuais tenham seus direitos de cidadania assegurados, é indispensável respeitar suas identidades de gênero, reconhecendo-lhes e garantindo-lhes o direito de serem tratadas segundo essas identidades de gênero e não simplesmente com base no nome do registro civil. Assim, se é um homem transexual, independentemente de ter nome de registro feminino, é preciso assegurar-lhe o direito de ser tratado pelo nome masculino com o qual se sente confortável e se identifica - e, do mesmo modo, se é uma mulher transexual ${ }^{\mathrm{III}}$.
\end{abstract}

Apesar de guardarem diferenças entre si, como na opção por aplicação de silicone, tratamento hormonal, realização da cirurgia de readequação sexual, entre outras demandas, as pessoas travestis e transexuais ao iniciarem a transformação e feminilização dos seus corpos sofrem da mesma violência que as excluem da escola, família, amigos e de todas as suas relações sociais que mantinham enquanto permaneciam com o corpo masculino. Embora utilizando o exemplo das mulheres trans, queremos alargar a esta noção para a transexualidade de um modo geral, envolvendo homens trans também nos desafios sociais que esse público enfrenta.

$\mathrm{Na}$ impossibilidade de obter uma formação escolar/profissional/universitária e a consequente exclusão do mundo formal do trabalho, restam pouquíssimas expectativas, em geral, sendo o único lugar possível para aquisição de renda e sustento pessoal é a prostituição ou, em alguns casos, o labor do trabalho informal com todos os seus problemas e precariedades. Embora esse pareça ser um caminho inevitável, muitas travestis e transexuais resistem à prostituição devido ao seu alto risco e exposição.

Benedetti ${ }^{\text {IV }}$ constatou que são raras as travestis idosas na cidade de Porto Alegre, no Rio Grande do Sul, pois muitas falecem ainda muito jovens devido a complicações relacionadas ao HIV/Aids ou são vítimas de violência. Infelizmente, esta não é uma 


\section{POLÍTICAS PÚBLICAS LGBT: UMA ANÁLISE DO PROGRAMA TRANSCIDADANIA DA PREFEITURA DE SÃO PAULO}

\section{ÉMERSON SILVA SANTOS E CLEYTON FEITOSA PEREIRA}

realidade apenas da cidade de Porto Alegre. $\mathrm{O}$ ambiente da prostituição, onde convive a maioria as travestis e transexuais, oferece um grande risco as suas vidas.

Ainda segundo Benedetti ${ }^{\mathrm{V}}$, em geral, ainda no início da puberdade as mulheres trans passam a utilizar vestimentas e se portarem como mulheres. Ou seja, o simples ato de desvelar e expressar sua identidade, algo comum para a população heterossexual, provoca forte rejeição das suas famílias que as expulsam de casa e cortam qualquer tipo de laço afetivo. A expulsão do lar familiar é mais um fator que colabora com o ingresso dessas pessoas para a prostituição, pois sem apoio da família e sem formação escolar e profissional restam possibilidades limitadas de sobrevivência.

Nesse sentido, Bento ${ }^{\mathrm{VI}}$ forja a noção de "cidadania precária", uma compreensão que reflete sobre a precariedade de políticas e legislações que reconheçam as necessidades específicas dessa população. Esse conceito pode ser ilustrado, por exemplo, a partir da criação do nome social enquanto alternativa burocráticoinstitucional que reconheça um dos elementos mais básicos dos seres humanos como o nome e o tratamento que as pessoas recebem. Nesse contexto, o nome social surge como uma resposta a ausência de uma norma que assegure a troca de nome civil, como é de desejo do Movimento Trans. Bento ainda aponta o Congresso Nacional brasileiro como uma das instâncias responsáveis pela negação de direitos a travestis e transexuais no país.

Diante dessa realidade social das pessoas trans e da atuação política dos movimentos LGBT, trans e de direitos humanos, algumas iniciativas governamentais vem surgindo no Brasil com vistas a tentar superar esse problema e garantir o acesso das pessoas trans aos serviços públicos e à condição de dignidade humana, prevista em inúmeros pactos e convenções internacionais. Políticas públicas que ofereçam tratamento de saúde, moradia, formação básica, profissional e social são imprescindíveis e vitais para proporcionar cidadania para este grupo.

\footnotetext{
A razão da existência das políticas públicas é o Estado Social, marcado pela obrigação de garantia de direitos fundamentais ao cidadão. Em síntese, as políticas públicas são, no estado democrático de direito, o meio que a administração pública dispõe para a defesa e concretização dos direitos de liberdade e dos direitos sociais dos cidadãos, direitos estes estabelecidos numa Constituição Nacional ${ }^{\mathrm{VII}}$.
}

Conforme refletido por Queiroz ${ }^{\mathrm{VIII}}$, as políticas públicas pretendem concretizar direitos sociais dos cidadãos e cidadãs, direitos já estabelecidos na Constituição Federal de 1988, cabendo assim ao Estado atuar de forma a implementar ações que assegurem os direitos sociais, civis, políticos, econômicos, entre outros, que os/as indivíduos/as possuem.

Compreendendo a situação de iminente vulnerabilidade social das travestis e transexuais, a Prefeitura de São Paulo lançou no dia 29 de janeiro de $2015^{\mathrm{IX}}$ o Programa TransCidadania, uma política pública municipal que tem como objetivo promover os direitos humanos e oferecer condições de recuperação e oportunidades a cem (100) travestis e transexuais em situação de vulnerabilidade social daquele município.

A Prefeitura de São Paulo foi pioneira no Brasil ao pensar uma política municipal de gênero e direitos humanos voltada especificamente para as pessoas travestis e transexuais. Nesse sentido, este estudo tem por objetivo fazer uma análise do Programa TransCidadania da Prefeitura de São Paulo, descrevendo suas ações e formas de atuação.

Cadernos do Tempo Presente, n. 28, abr./jun. 2017 p. 54-63 | http://www.seer.ufs.br/index.php/tempo. 


\section{POLÍTICAS PÚBLICAS LGBT: UMA ANÁLISE DO PROGRAMA TRANSCIDADANIA DA PREFEITURA DE SÃO PAULO}

\section{ÉMERSON SILVA SANTOS E CLEYTON FEITOSA PEREIRA}

Desta maneira, a relevância deste trabalho justifica-se na necessidade contemporânea de refletir sobre a cidadania da população LGBT e de iniciativas públicas que visem assegurar a sua cidadania e combatam desigualdades sociais históricas envolvendo este segmento. Analisar ações oriundas de governos também se torna muito útil, tanto para pensar nos seus impactos quanto para monitorar o seu desenvolvimento.

\section{Escolhas metodológicas}

No presente estudo, optamos por utilizar a abordagem qualitativa, por esta ser a perspectiva que mais se adequou. Segundo Gonsalves $X$ "A pesquisa qualitativa preocupa-se com a compreensão, com a interpretação do fenômeno, considerando o significado que os outros dão às suas práticas, o que impõe ao pesquisador uma abordagem hermenêutica". Creswell ${ }^{\mathrm{XI}}$ reflete que o modelo qualitativo emprega algumas estratégias de coleta e análise de dados, podendo se basear em textos. Assim, o método qualitativo se propõe e apresentar uma análise e interpretação dos dados, colaborando com o objetivo deste trabalho.

Este é um estudo descritivo. O objetivo da pesquisa descritiva é descrever as características de determinadas populações, fenômenos ou suas variáveis ${ }^{\mathrm{XII}}$. Segundo Gil "Algumas pesquisas descritivas vão além da simples identificação da existência de relações entre variáveis e pretendem determinar a natureza dessa relação"XIII. Nesse sentido, este estudo faz uma análise e apresenta uma descrição do Programa TransCidadania.

Tomando como base a proposta metodológica apresentada por Gil ${ }^{\mathrm{XIV}}$, utilizamos a pesquisa documental como técnica de coleta de dados. Para isso, foi considerado o Decreto 55.874/2015, instrumento legal de criação do Programa TransCidadania para a coleta dos dados necessários para a pesquisa.

As fontes documentais fornecem ao/à pesquisador/a a possibilidade de investigar os dados em quantidade e qualidade suficientes, na medida em que evitam $o$ constrangimento que por ventura podem ocorrer na aplicação de entrevistas e questionários diretamente com as pessoas ${ }^{\mathrm{XV}}$. Além disso, por este programa, o TransCidadania ser um projeto piloto e ainda não ter sido executado completamente, só nos resta a possibilidade de compreender a sua formatação e os seus objetivos dentro do que está exposto em sua normativa. Com isso, defendemos o desenvolvimento de pesquisas que avaliem os seus efeitos, potencialidades e desafios ao término do mesmo, consultando gestores/as responsáveis pela execução do mesmo e o público beneficiário.

Além do Decreto 55874/2015, também utilizamos notícias relacionadas ao Programa TransCidadania publicadas no site oficial da Prefeitura de São Paulo ${ }^{\text {XVI }}$ e outras notícias veiculadas na imprensa ${ }^{\mathrm{XVII}}$. Isso se faz necessário, tendo em vista $\mathrm{o}$ lançamento recente dessa política pública e a quantidade ainda escassa de documentos e fontes sobre o TransCidadania.

\section{TransCidadania: uma política de reconhecimento}

Tendo em vista a situação de iminente vulnerabilidade social de travestis e transexuais, a Prefeitura da cidade de São Paulo resolveu elaborar uma política pública voltada para essa população. Compreendemos o conceito de política pública aqui como uma definição empregada por Secchi ${ }^{\mathrm{XVIII}}$, segundo a qual: 


\section{POLÍTICAS PÚBLICAS LGBT: UMA ANÁLISE DO PROGRAMA TRANSCIDADANIA DA PREFEITURA DE SÃO PAULO}

\section{ÉMERSON SILVA SANTOS E CLEYTON FEITOSA PEREIRA}

Uma política pública é uma diretriz elaborada para enfrentar um problema público. Vejamos essa definição em detalhe: uma política é uma orientação à atividade ou à passividade de alguém (...). Uma política pública possui dois elementos fundamentais: intencionalidade pública e resposta a um problema público; em outras palavras, a razão para o estabelecimento de uma política pública é o tratamento ou a resolução de um problema entendido como coletivamente relevante ${ }^{\mathrm{XIX}}$.

Portanto, políticas afirmativas de gênero, diversidade sexual, raça, entre outras, são elaboradas com o escopo de solucionar problemas sociais. Por isso é tão importante a pressão exercida pelos movimentos sociais haja visto que suas estratégias de denúncia social poderão originar políticas públicas $\mathrm{XX}$. O programa TransCidadania, nosso objeto de estudo, foi criado pelo Decreto 55.874 de 29 de Janeiro de 2015, sancionado pelo então Prefeito da capital paulista, Fernando Haddad, do Partido dos Trabalhadores (PT). Seu lançamento também ocorreu no dia 29 de janeiro, data em que se comemora o dia da nacional da visibilidade trans.

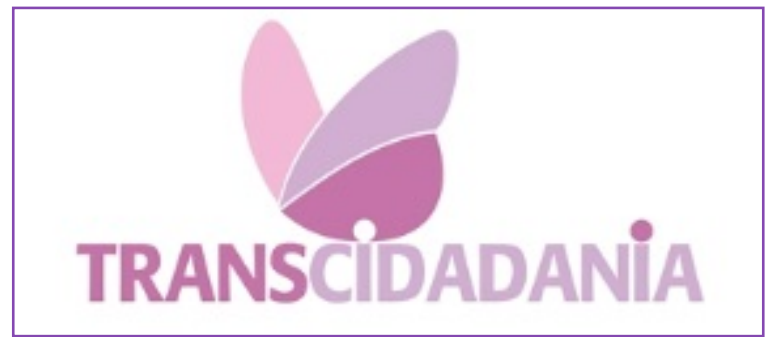

Figura 1 - Marca oficial do Programa TransCidadania da Prefeitura de São Paulo.

A imagem contida na Figura 1 é relevante para o objeto de estudo em análise, pois simboliza metaforicamente a metamorfose e a saída do casulo das borboletas em alusão à transformação corporal e identitária vivenciado pelas travestis e transexuais. Ela também representa a liberdade, valor reivindicado pelo Movimento de Travestis e Transexuais no Brasil.

Segundo o Decreto de criação do programa, seu objetivo é promover os direitos humanos, o acesso à cidadania, bem como a qualificação e humanização do atendimento prestado a travestis e transexuais em situação de vulnerabilidade social ${ }^{\mathrm{XXI}}$.

$\mathrm{O}$ Artigo $2^{\circ}$ define as quatro diretrizes que orientam as ações do TransCidadania:

I - Oferta de condições de autonomia financeira e combate à pobreza, por meio da elevação da escolaridade, acesso a programas sociais de redistribuição de renda, qualificação profissional e a intermediação de mão de obra.

II - Desenvolvimento de ações que combatam e enfrentem o preconceito contra travestis e transexuais e que promovam o respeito à expressão da sua identidade de gênero e respeito à utilização do nome social.

III - Promoção de formação continuada e sensibilização dos/das servidores/as da Prefeitura de São Paulo com o objetivo de garantir um atendimento humanizado e qualificado a pessoas travestis e transexuais, observando os princípios constitucionais da dignidade da pessoa humana, da igualdade e da não revitimização.

IV- Oferta de formação cidadã em direitos humanos para pessoas travestis e transexuais com o objetivo de promover o exercício da cidadania, participação popular e controle social exercido por estas pessoas.

Cadernos do Tempo Presente, n. 28, abr./jun. 2017 p. 54-63 | http://www.seer.ufs.br/index.php/tempo. 


\section{POLÍTICAS PÚBLICAS LGBT: UMA ANÁLISE DO PROGRAMA TRANSCIDADANIA DA PREFEITURA DE SÃO PAULO}

\section{ÉMERSON SILVA SANTOS E CLEYTON FEITOSA PEREIRA}

Segundo o site da Prefeitura da Cidade de São Paulo XXII , o programa inicialmente atende a 100 travestis e transexuais e atua em três frentes de atuação, sendo elas: autonomia, oportunidades e cidadania.

Autonomia com a inclusão no CAD Único, Programa Bolsa Família e concessão de uma bolsa mensal no valor de $\mathrm{R} \$ 840,00$. A bolsa tem o objetivo de conceder um rendimento para que as travestis e transexuais possam concluir a ensino básico através da Educação de Jovens e Adultos (EJA) e do Exame Nacional do Ensino Médio (ENEM), oferendo assim oportunidades profissionais e/ou ingresso no Ensino Superior.

A concessão de um auxílio financeiro para que as beneficiárias possam se dedicar aos estudos é um elemento central dessa política, pois sem o auxílio financeiro da Prefeitura as travestis teriam que continuar trabalhando a noite na prostituição para se sustentarem e não conseguiriam estudar. Segundo Benedetti ${ }^{X X I I I}$, a maioria das travestis e transexuais mesmo trabalhando na prostituição passam por grandes dificuldades financeiras, tendo em vista que precisam custear seu sustento e investir em vestimentas, maquiagens e demais acessórios, elementos necessários para uma profissão que está em jogo o desejo, a sedução e concorrência.

Oportunidades garantidas através do acesso ao Ensino Fundamental e Médio pela EJA, acesso aos cursos do Programa Nacional de Ensino Técnico (Pronatec) e introdução ao mundo do trabalho e estágio, concedendo outras oportunidades para além da prostituição XXIV . $^{\text {. }}$

Cidadania por meio da oferta de curso de Cidadania, Direitos humanos e Democracia, respeito ao nome social, preparação e adequação de serviços, espaços e equipamentos públicos da saúde, educação e assistência social da Prefeitura de São Paulo.

O Decreto 55874/2015 define no seu artigo terceiro que cabe a Secretaria Municipal de Direitos Humanos e Cidadania da Prefeitura de São Paulo (SDHC/SP), acompanhar, avaliar e articular as demais secretarias municipais para execução do programa, encaminhar as pessoas beneficiárias do programa TransCidadania a outros programas, benefícios e políticas públicas que as mesmas fizerem jus, referenciar as redes municipais de saúde, assistência social e da mulher para atendimento e acolhimento das pessoas trans, prestar o apoio técnico e financeiro necessário à execução do programa.

A SDHC/SP exerce um papel central na implementação dessa política pública, tendo em vista que é atribuição deste órgão a execução, acompanhamento, articulação e avaliação do programa. Isso demostra que o TransCidadania é uma política pública municipal de Direitos Humanos.

Ainda segundo informações do site da Prefeitura de São Paulo, além da SDHC/SP, outras cinco Secretarias Municipais (Saúde, Educação, Desenvolvimento, Trabalho e Empreendedorismo, Políticas para as Mulheres, Assistência e Desenvolvimento Social) também atuam com ações específicas e recursos próprios no Programa TransCidadania.

À Secretaria de Educação cabe a regulamentação do uso do nome social na rede municipal de ensino. Já a Secretaria de Políticas para as Mulheres presta atendimento prioritário a travestis e transexuais vítimas de violência doméstica no Centro de Referência da Mulher (CRM). A inclusão das beneficiárias do programa no mundo do trabalho é de responsabilidade da Secretaria de Desenvolvimento, Trabalho e Empreendedorismo. Compete a Secretaria de Assistência e Desenvolvimento Social o acolhimento de travestis e transexuais em Casas Abrigo da Prefeitura de São Paulo. A 


\section{POLÍTICAS PÚBLICAS LGBT: UMA ANÁLISE DO PROGRAMA TRANSCIDADANIA DA PREFEITURA DE SÃO PAULO}

\section{ÉMERSON SILVA SANTOS E CLEYTON FEITOSA PEREIRA}

Secretaria de Saúde oferta hormonoterapia (tratamento hormonal) conforme estabelecido no Art. $4^{\circ}$ do Decreto 55874/2015.

Isso demostra a perspectiva intersetorial e transversal do Programa Transcidadania, onde são oferecidos ações e serviços por várias secretarias. A SDHC/SP além de financiar a política, também deve articular ações e serviços de outras secretarias municipais. Inojosa ${ }^{X X V}$ aponta que a proposta de intersetorialidade fortalece as políticas públicas na medida em que tem consequência no planejamento e no orçamento.

Quanto maior o número de secretarias e órgãos públicos envolvidos, provavelmente será maior o número de ações e volume de recursos investidos no programa. Entretanto, consideramos também que quanto maior o número de órgãos envolvidos, maior é o desafio da articulação, considerando fatores múltiplos como as disputas político-partidárias em governos de coalização, a abertura de outras Secretarias para segmentos estigmatizados como é o caso da população LGBT e até questões materiais e logísticas como a ausência de uma estrutura que comporte essa necessidade de articulação como transportes, motoristas, telefones, entre outros. Parece pouca coisa, mas quando pensamos numa cidade com as dimensões de São Paulo, o mero deslocamento para uma reunião presencial torna-se uma barreira a ser enfrentada.

\section{Considerações finais}

Este trabalho teve o objetivo de analisar o Programa TransCidadania da Prefeitura de São Paulo, descrevendo suas ações e formas de atuação a partir de uma leitura e interpretação sobre o seu Decreto de criação.

Desta maneira, os achados indicam que se trata de uma política afirmativa das identidades trans (travestis e transexuais) com foco naquelas pessoas em situação de vulnerabilidade social. Este direcionamento é importante se considerarmos o recorte de classe envolvendo esta população, pois ao mesmo tempo em que muitas são empurradas para a marginalidade, outras estão inseridas nos altos estratos paulistanos, seja ocupando espaços privilegiados como programas televisivos, seja brilhando com suas performances em festas e bailes de alto nível.

O TransCidadania é um projeto piloto, em fase de experimentação, e atende um público ainda restrito se visualizarmos o universo de pessoas trans excluídas naquela megalópole. No entanto, se mostra como uma primeira experiência exitosa do ponto de vista da política pública observando que temos poucas iniciativas como esta no país afora, conferindo-lhe status ousado e vanguardista.

O Programa incide sobre várias Secretarias e órgãos de governo revelando uma concepção interessante de transversalidade das políticas públicas e avaliamos que, se por um lado esta perspectiva se adequa ao conjunto de necessidades da população trans (na medida em que há precariedades no acesso a direitos variados básicos), por outro, esta formatação apresenta desafios a serem superados haja visto o pensamento positivista e cartesiano próprios do pensamento da modernidade ocidental. Assim, vivenciamos uma mudança de paradigma em que se fragilizam a atomização dos espaços, a fragmentação e o isolamento das áreas e dos órgãos e se fortalece o diálogo, a integração, o pensamento complexo e a transversalidade nas relações.

\section{Notas}

Cadernos do Tempo Presente, n. 28, abr./jun. 2017 p. 54-63 | http://www.seer.ufs.br/index.php/tempo. 


\section{POLÍTICAS PÚBLICAS LGBT: UMA ANÁLISE DO PROGRAMA TRANSCIDADANIA DA PREFEITURA DE SÃO PAULO}

\section{ÉMERSON SILVA SANTOS E CLEYTON FEITOSA PEREIRA}

\footnotetext{
${ }^{\text {I }}$ Doutorando em Ciências Sociais pela Universidade Federal de Campina Grande - UFGC. Mestre em Educação Contemporânea pela Universidade Federal de Pernambuco - UFPE. Bacharel em Administração Pública pela Universidade Federal Rural de Pernambuco - UFRPE e Especialista em Administração Pública - UCAM.

II Doutorando em Ciência Política pela Universidade de Brasília - UnB. Mestre em Direitos Humanos pela Universidade Federal de Pernambuco - UFPE. Licenciado em Pedagogia pela Universidade Federal de Pernambuco/Centro Acadêmico do Agreste - UFPE/CAA. É autor do livro Políticas Públicas LGBT e Construção Democrática no Brasil (Editora Appris, 2017).

III CARVALHO, ANDRADE E JUNQUEIRA, 2009, p. 46 e 47.

IV 2005.

$\mathrm{V} 2005$.

VI 2014 .

VII QUEIROZ, 2009, p. 86.

VIII 2009.

IX O dia 29 de Janeiro é considerado o dia Nacional da Visibilidade Trans por entidades nacionais do Movimento Trans, como a Articulação Nacional de Travestis e Transexuais (ANTRA), por exemplo. X 2003, p. 68 .

XI 2007.

XII VERGARA, 2000.

XIII 2008, p. 42.

XIV 2008.

XV GIL, 2008

${ }^{X V I}$ http://www.capital.sp.gov.br. Acesso em: 04/01/2018.

XVII Para ter dimensão da repercussão e acessar as notícias, visualizar:
}

Carta Capital - Prefeitura lança programa de apoio a transexuais http://www.cartacapital.com.br/sociedade/prefeitura-lanca-programa-de-insercao-social-as-mulherestransexuais-582.html. Acesso em: 04/01/2018.

Estadão - Prefeitura vai pagar bolsas de $\mathrm{R} \$ 840,00$ para travestis $\mathrm{e}$ transexuais http://educacao.estadao.com.br/noticias/geral,prefeitura-vai-pagar-bolsas-de-r-840-para-travestis-etransexuais, 1626421. Acesso em: 04/01/2018.

Portal G1 da Globo - Travestis podem ganhar bolsa estudo e tratamento hormonal em São Paulo http:/g1.globo.com/sao-paulo/noticia/2015/01/travestis-podem-ganhar-bolsa-estudo-e-tratamentohormonal-em-sao-paulo.html. Acesso em: 04/01/2018.

Diário de São Paulo - Programa Transcidadania é lançado pela Prefeitura http:/www.diariosp.com.br/noticia/detalhe/77782/programa-transcidadania-e-lancado-pela-prefeitura. Acesso em: 04/01/2018.

Folha de São Paulo - Prefeitura de São Paulo dá bolsa para travesti completar educação básica http://www1.folha.uol.com.br/cotidiano/2015/01/1582178-prefeitura-de-s-paulo-da-bolsa-para-travesticompletar-educacao-basica.shtml. Acesso em: 04/01/2018. XVIII 2013.

XIX SECCHI, 2013, p. 2 e 11

XX FEITOSA, 2017.

XXI PREFEITURA DA CIDADE DE SÃO PAULO, 2015.

${ }^{X X I I} \mathrm{http}: / / w w w . c a p i t a l . s p . g o v . b r / p o r t a l / n o t i c i a / 5276 \#$ ad-image-0. Acesso em: 04/01/2018.

XXIII 2005 .

XXIV Queremos expressar que consideramos a prostituição um exercício profissional tão digno quanto qualquer outro e a nossa defesa é que este labor seja acionado como uma opção e não como uma obrigação fatal, um destino inato de todas as pessoas trans do Brasil. Portanto, entendemos que políticas afirmativas para a população trans devem ser desenvolvidas para possibilitar a elas outras oportunidades na vida, incluindo a prostituição.

XXV INOJOSA, Rose Marie. Sinergia em políticas e serviços públicos: desenvolvimento social

com intersetorialidade. Cadernos Fundap, n. 22., 2001. p. 102-110. Disponível em: $<$ http://publicacoes.fundap.sp.gov.br/cadernos/cad22/dados/Inojosa.pdf $>$. Acesso em: 04/01/2018.

\section{Referências}

Cadernos do Tempo Presente, n. 28, abr./jun. 2017 p. 54-63 | http://www.seer.ufs.br/index.php/tempo. 


\section{ÉMERSON SILVA SANTOS E CLEYTON FEITOSA PEREIRA}

BENEDETTI, Marcos Renato. Toda feita: o corpo e o gênero das travestis. Rio de Janeiro: Garamond, 2005.

BENTO, Berenice. Nome social para pessoas trans: cidadania precária e gambiarra legal.

Contemporânea - Revista de Sociologia da UFSCar, São Carlos, v. 4, n. 1, jan.-jun. 2014, p. 165-182.

BUTLER, Judith. Problemas de gênero: feminismo e subversão da identidade. Rio de Janeiro: Civilização Brasileira, 2003.

CARVALHO, Maria Eulina Pessoa de; ANDRADE, Fernando Cézar Bezerra de; JUNQUEIRA, Rogério Diniz. Gênero e diversidade sexual: um glossário. João Pessoa: Ed. Universitária UFPB, 2009.

CRESWELL, John W. Projeto de pesquisa: métodos qualitativo, quantitativo e misto. Porto Alegre: Artmed, 2007.

FEITOSA, Cleyton. Políticas públicas LGBT e construção democrática no Brasil. Curitiba: Appris, 2017.

GIL, Antônio Carlos. Métodos e técnicas de pesquisa social. 6 ed. São Paulo: Atlas, 2008.

GONSALVES, Elisa Pereira. Conversas sobre iniciação à pesquisa científica. 3.ed. Campinas, SP: Alínea. 2003.

INOJOSA, Rose Marie. Sinergia em políticas e serviços públicos: desenvolvimento social

com intersetorialidade. Cadernos Fundap, n. 22., 2001. p. 102-110. Disponível em: $<$ http://publicacoes.fundap.sp.gov.br/cadernos/cad22/dados/Inojosa.pdf $>$. Acesso em: 04/01/2018.

PERES, William. Cenas de Exclusões anunciadas: travestis, transexuais, transgêneros e a escola brasileira. In: Junqueira, Rogério Diniz (Org.), Diversidade sexual na educação: problematizações sobre a homofobia nas escolas. Brasília: Ministério da Educação, Secretaria da Educação Continuada, Alfabetização e diversidade, UNESCO. 2009.

QUEIROZ, Roosevelt Brasil. Formação e Gestão de Políticas Públicas. Curitiba: Ibpex, 2009.

SÃO PAULO. Decreto $N^{o} 55.874$ de 29 de Janeiro de 2015. Institui o Programa TransCidadania, destinado à promoção da cidadania de travestis e transexuais em situação de vulnerabilidade social; altera disposições dos Decretos $n^{0} 44.484$, de 10 de março de 2004, e $\mathbf{n}^{0}$ 40.232, de 2 de janeiro de 2001. Disponível em: 
POLÍTICAS PÚBLICAS LGBT: UMA ANÁLISE DO PROGRAMA TRANSCIDADANIA DA PREFEITURA DE SÃO PAULO

\section{ÉMERSON SILVA SANTOS E CLEYTON FEITOSA PEREIRA}

$<$ http://www3.prefeitura.sp.gov.br/cadlem/secretarias/negocios_juridicos/cadlem/integr a.asp?alt=30012015D\%20558740000> . Acesso em: 04/01/2018.

SECCHI, Leonardo. Políticas públicas: conceitos, esquemas de análise, casos práticos. São Paulo: Cengage Learning, 2013.

VERGARA, Sylvia Constant. Projetos e relatórios de pesquisa em administração. 3 . ed. São Paulo: Atlas, 2000. 